Case Report

\title{
A Novel Mutation of the CYP11B2 in a Saudi Infant with Primary Hypoaldosteronism
}

\author{
Lama Alfaraidi, ${ }_{1}^{1}$ Abrar Alfaifi, ${ }^{1}$ Rawan Alquaiz, ${ }^{1}$ Faten Almijmaj, ${ }^{2}$ and Horia Mawlawi \\ ${ }^{1}$ College of Medicine, King Saud University, Riyadh, Saudi Arabia \\ ${ }^{2}$ Department of Pediatrics, Prince Sultan Military Medical City, Riyadh 11159, Saudi Arabia \\ Correspondence should be addressed to Lama Alfaraidi; lama.al.faraidi@gmail.com
}

Received 29 July 2017; Accepted 26 September 2017; Published 23 October 2017

Academic Editor: Takeshi Usui

Copyright (C) 2017 Lama Alfaraidi et al. This is an open access article distributed under the Creative Commons Attribution License, which permits unrestricted use, distribution, and reproduction in any medium, provided the original work is properly cited.

Isolated hypoaldosteronism is a rare autosomal recessive disease presenting with severe salt wasting and failure to thrive in infancy. A 6-month-old Saudi girl born to consanguineous parents was referred from primary health care for failure to thrive and developmental delay. Laboratory tests revealed hyponatremia, hyperkalemia, and metabolic acidosis with high renin and low aldosterone. Blood samples were collected for endocrine and genetic studies. Sequence analysis of the CYP11B2 revealed a T to A transition at position $1398+2$ in exon 8 of the gene in a homozygous state (c.1398+T>A). This result was confirmed by sequencing an independent PCR product. Given the position of the transition at a highly conserved nucleotide and the predictions of different bioinformatic algorithms, it is likely that the mutation is the pathogenic cause of this condition. This result was compared with the reference NM_000498.3. Here, we report a novel homozygous mutation resulting in aldosterone synthase deficiency. To the best of our knowledge, this mutation has not been described in the literature or in any database thus far. The mutation manifested as a rare inherited disease in an infant exhibiting critical salt loss. An adequate replacement treatment will give a good long-term prognosis.

\section{Background}

Aldosterone is a hormone exhibiting potent mineralocorticoid activity that is synthesized in the zona glomerulosa of the adrenal gland and is responsible for maintaining electrolyte balance and intravascular volume [1].

CYP11B1 (11b-hydroxylaze) and CYP11B2 (aldosterone synthase), which share more than $90 \%$ of their amino acid sequences, encode the enzymes responsible for the three terminal steps in aldosterone formation [2]. CYP11B2 is located on chromosome $8 \mathrm{q} 24$ and catalyzes three reactions: the 11-hydroxylation of deoxycorticosterone (DOC) to corticosterone, the 18-hydroxylation of corticosterone to 18 hydroxycorticosterone (18-OHB), and the 18-oxidation of 18hydroxycorticosterone to aldosterone $[3,4]$.

Congenital isolated hypoaldosteronism, formerly known as corticosterone methyloxidase deficiency (CMO), is a rare autosomal recessive disorder caused by aldosterone synthase deficiency (ASD) [3]. Most cases have been attributed to approximately 80 different mutations within CYP11B2.
Patients with this deficiency experience recurrent dehydration, salt wasting, and failure to thrive [4]. ASD is subdivided into CMO types I and II, both of which are characterized by low aldosterone levels and elevated renin activity, accompanied by the accumulation of steroid precursors prior to a biosynthetic block. CMO I is characterized by low levels of 18hydroxycorticosterone, whereas CMO II is characterized by high levels of $18-\mathrm{OHB}$ and an increase of the urinary excretion of the major metabolite of 18-OHB [3].

ASD has been identified in Jews of European, North American, and Iranian descent [3]. In Asians, it has been reported among Thai [5], Indian [5], and Japanese [6] populations. In this paper, we present a case of isolated primary hypoaldosteronism in a 6-month-old Saudi female infant and the results of her CYP11B2 analysis.

\section{Case Report}

A female infant born to consanguineous Saudi parents presented at 6 months of age to primary health care workers with 
TABLE 1: Growth parameters progression.

\begin{tabular}{|c|c|c|c|c|}
\hline $\begin{array}{l}\text { Growth } \\
\text { parameters }\end{array}$ & $\begin{array}{l}\text { On admission } \\
\text { at } 6 \text { months }\end{array}$ & $\begin{array}{l}\text { After } 6 \text { months } \\
\text { at } 12 \text { months }\end{array}$ & $\begin{array}{l}\text { After } 1 \text { year } \\
\text { at } 18 \text { months }\end{array}$ & $\begin{array}{l}\text { Recently } \\
\text { at } 2 \text { years }\end{array}$ \\
\hline Weight & $-5.20 \mathrm{SD}(3.6 \mathrm{~kg})$ & $-2.80 \mathrm{SD}(7.1 \mathrm{~kg})$ & $-0.64 \mathrm{SD}(10.3 \mathrm{~kg})$ & $-0.67 \mathrm{SD}(11.3 \mathrm{~kg})$ \\
\hline Height & $-3.90 \mathrm{SD}(55 \mathrm{~cm})$ & $-1.99 \mathrm{SD}(68 \mathrm{~cm})$ & $-1.00 \mathrm{SD}(77 \mathrm{~cm})$ & $-0.40 \mathrm{SD}(84.7 \mathrm{~cm})$ \\
\hline
\end{tabular}

TABLE 2: Laboratory investigations.

\begin{tabular}{lcr}
\hline Test & Result & Normal reference level \\
\hline Sodium & $128 \mathrm{mmol} / \mathrm{L}$ & $135-145 \mathrm{mmol} / \mathrm{L}$ \\
Potassium & $7 \mathrm{mmol} / \mathrm{L}$ & $3.6-5.2 \mathrm{mmol} / \mathrm{L}$ \\
Corrected calcium & $2.6 \mathrm{mmol} / \mathrm{L}$ & $2.1-2.6 \mathrm{mmol} / \mathrm{L}$ \\
Bicarbonate & $15.5 \mathrm{mEq} / \mathrm{L}$ & $22-28 \mathrm{mEq} / \mathrm{L}$ \\
Cortisol (prestimulation) & $761 \mathrm{nmol} / \mathrm{L}$ & $140-700 \mathrm{nmol} / \mathrm{L}$ \\
Cortisol (poststimulation) & $1305 \mathrm{nmol} / \mathrm{L}$ & \\
ACTH & $5.6 \mathrm{Pmol} / \mathrm{L}$ & $1.6-13.9 \mathrm{Pmol} / \mathrm{L}$ \\
Dehydroepiandrosterone & $0.118 \mathrm{nmol} / \mathrm{L}$ & $0.090-3.350 \mathrm{nmol} / \mathrm{L}$ \\
$17-H y d r o x y p r o g e s t e r o n e$ & $2.3 \mathrm{mmol} / \mathrm{L}$ & $0-5 \mathrm{nmol} / \mathrm{L}$ \\
Renin & $3310 \mathrm{pmol} / \mathrm{L}$ & $0.15-3.53 \mathrm{pmol} / \mathrm{L}$ \\
Aldosterone & $68.4 \mathrm{pmol} / \mathrm{L}$ & $139-3660 \mathrm{pmol} / \mathrm{L}$ \\
\hline
\end{tabular}

failure to thrive and developmental delay. Routine laboratory investigations revealed hyponatremia with hyperkalemia. The infant was delivered prematurely by C-section at 32 weeks with a birth weight $2.4 \mathrm{~kg}$. The child was referred to the Prince Sultan Medical Military Hospital Emergency Center for treatment by an endocrinologist.

On admission, the patient was not dehydrated, and the vital signs were normal. Her weight and length were both below 3rd centile, weight was $3.6 \mathrm{~kg}(-5.2 \mathrm{SD})$, and length was $55 \mathrm{~cm}(-3.9 \mathrm{SD})$ (Table 1). The systemic examination results were normal; no hyperpigmentation was observed, and the external genitalia were normal. Regarding the patient's development, she was experiencing global developmental delay. She was not able to support her head or hold objects, was not cooing or laughing, had no social smile, and did not recognize her mother. The results of initial investigations were as follows: $\mathrm{Na} 128 \mathrm{mmol} / \mathrm{L}, \mathrm{K} 7 \mathrm{mmol} / \mathrm{L}$, corrected calcium (CC) $2.6 \mathrm{mmol} / \mathrm{L}$, bicarbonate $15.5 \mathrm{mmol} / \mathrm{L}$, and normal renal function. An adrenocorticotropic hormone (ACTH) stimulation test was performed: before test, the cortisol level was $761 \mathrm{nmol} / \mathrm{L}$ and the ACTH level was $5.6 \mathrm{nmol} / \mathrm{L}$ (normal), while after test, the cortisol level was $1305 \mathrm{nmol} / \mathrm{L}$, the dehydroepiandrosterone level was $0.118 \mathrm{nmol} / \mathrm{L}(0.090-3.350)$, the renin level was $3310 \mathrm{pmol} / \mathrm{L}(0.15-3.53)$, and the aldosterone level was 68.4 (139-3660 pmol/L). A 17-hydroxyprogesterone test was normal (Table 2).

Based on the infant's clinical presentation and test results, she was diagnosed with primary hypoaldosteronism. The patient improved clinically, both growth and psychomotor development have matched her chronological age of 2 years, and biochemically when treated with $0.1 \mathrm{mg}$ fludrocortisone twice daily and $1 \mathrm{ml} \mathrm{NaCl}$ delivered orally three times per day.

\section{Methods}

3.1. Genetic Study. Molecular genetic analysis of CYP11B2 was performed. Written informed consent was obtained from the patient's parents. A blood sample was obtained from which DNA was extracted, and molecular genetic analysis of CYP11B2 was performed. CYP11B2 (OMIM 124080) exons 1-9 and their respective exon-intron boundaries were amplified by PCR and analyzed by direct sequencing. The resulting sequence data were compared with the reference sequence (NM_000498.3). The patient carried the homozygous mutation c.1398+2T $>A(p$ ??) in CYP11B2 (Figure 1). The result was confirmed by sequencing of an independent PCR product. Prediction of potential pathogenic effect of the detected mutation was performed utilizing ESE finder (http:// krainer01.cshl.edu/cgi-bin/tools/ESE3/esefinder.cgi) [7] and Fruit Fly (http://www.fruitfly.org/) [8].

\section{Discussion}

We describe an infant girl who presented with failure to thrive, poor feeding, and developmental delay. Laboratory tests revealed hyponatremia and hyperkalemia, metabolic acidosis, normal cortisol levels, and high renin and low aldosterone levels. Genetic testing confirmed a diagnosis of primary hypoaldosteronism. The patient improved dramatically after treatment with fludrocortisone.

The ASD (CYP11B2) encodes the steroid 11/18 B hydroxylase and is expressed in the zona glomerulosa of the adrenal gland, where it synthesizes the mineralocorticoid aldosterone. ASD type I (CMO type I) is caused by a deficiency in the 18-hydroxylase enzyme, which results in low levels of 


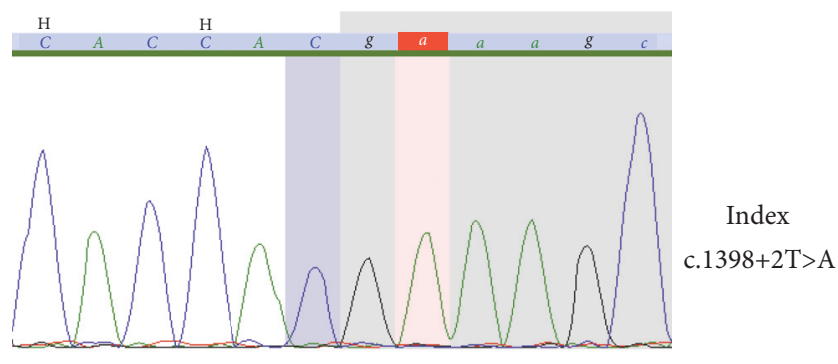

Exon 8 Intron 8

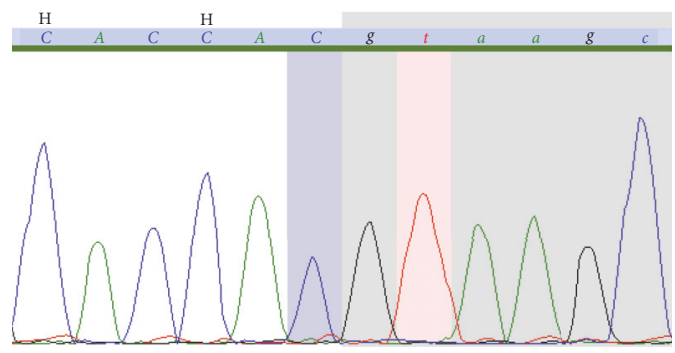

FIGURE 1: Chromatography.

$\mathrm{OHB}$ and aldosterone and low urinary metabolites; in ASD type II (CMO II), 18- OHB levels are markedly elevated, and the levels of aldosterone and its urinary metabolites are low [3]. The plasma renin activity levels are low in both disorders. The ratio of plasma 18 - OHB/aldosterone can be differentiated between the two disorders, but this biochemical phenotype has overlapping features and is better considered a continuous spectrum of the same disease $[5,9]$.

Patients with ASD experience recurrent dehydration, salt wasting, and failure to thrive [4]. The clinical picture varies with age and is most severe during infancy. The severity of salt wasting decreases with age, but the abnormal steroid pattern persists throughout life, possibly due to increases in mineralocorticoid sensitivity and sodium intake with age [10]. However, the initial presentation of life-threating salt wasting that is a hallmark of ASD can be differentiated biochemically from defects in steroid biosynthesis, such as congenital adrenal hyperplasia with salt loss [11].

Primary hypoaldosteronism can be caused by different defects in CYP11B2, such as nonsense, missense, and frame shift mutations $[10,11]$. However, in this case, we discovered a novel mutation in CYP11B2 that caused aldosterone deficiency. Genetic analysis revealed a $\mathrm{T}$ to $\mathrm{A}$ transition at position c.1398+2 in the homozygous state (c.1398+2T>A). Given the position of the transition at a highly evolutionarily conserved nucleotide and the predictions of different bioinformatic algorithms, it is likely that the mutation is pathogenic. The nucleotide exchange is located in intron 8 and affects the donor splice site of exon 8 . A computer-based comparison of the modified donor splice site of exon 8 of CYP11B2 with the wild-type sequence was performed using different bioinformatic tools. This analysis revealed a loss of the constitutive donor splice site of exon 8 due to the alteration c.1398+2T $>$ A. Although sequencing analysis cannot exclude a large heterozygous deletion in the CYP11B2 gene in trans to c.1398+2T >A (i.e., hemizygosity), homozygosity of c. $1398+2 \mathrm{~T}>\mathrm{A}$ is most likely.

Both homozygosity and hemizygosity of c.1398+2T $>$ A in the CYP11B2 gene would be compatible with the clinical diagnosis of primary hypoaldosteronism in this patient. To distinguish between homozygosity and compound heterozygosity for c.1398+2T $>$ A with a large deletion comprising this position on the other allele, we are in the process of sequencing the parents' DNA for the mutation.

\section{Conclusion}

To the best of our knowledge, this is the first reported case of a Saudi infant with aldosterone synthase deficiency due to a homozygous alteration (c.1398+2T $>\mathrm{A})$ in CYP11B2 that has not been described in the literature or any databases thus far. Although it is a rare inherited disease, there is a high index of suspicion of cases with life-threating salt wasting in infancy because of dramatic clinical improvements and good longterm prognosis can be achieved with replacement treatment.

\section{Additional Points}

Limitations. We could not differentiate between biochemical types of ASD due to limited resources. The results of genetic testing of the parents are forthcoming.

\section{Conflicts of Interest}

The authors declare that there are no conflicts of interest regarding the publication of this paper.

\section{References}

[1] M. H. Bassett, P. C. White, and W. E. Rainey, "The regulation of aldosterone synthase expression," Molecular and Cellular Endocrinology, vol. 217, no. 1-2, pp. 67-74, 2004.

[2] E. Mornet, J. Dupont, A. Vitek, and P. C. White, "Characterization of two genes encoding human steroid $11 \beta$-hydroxylase (P-450(11 $\beta)$ )," The Journal of Biological Chemistry, vol. 264, no. 35, pp. 20961-20967, 1989.

[3] P. C. White, "Aldesterone synthase deficiency and related disorder," Molecular and Cellular Endocrinology, 18187, 2004.

[4] S. Ulick, J. Z. Wang, and D. H. Morton, "The biochemical phenotypes of two inborn errors in the biosynthesis of aldosterone," The Journal of Clinical Endocrinology \& Metabolism, vol. 74, no. 6, pp. 1415-1420, 1992.

[5] T. Klomchan, V. Supornsilchai, S. Wacharasindhu, V. Shotelersuk, and T. Sahakitrungruang, "Novel CYP11B2 mutation causing aldosterone synthase (P450c11AS) deficiency," European Journal of Pediatrics, vol. 171, no. 10, pp. 1559-1562, 2012.

[6] E. Kondo, A. Nakamura, K. Homma et al., "Two novel mutations of the CYP11B2 gene in a Japanese patient with aldosterone deficiency type 1," Endocrine Journal, vol. 60, no. 1, pp. 51-55, 2013.

[7] http://krainer01.cshl.edu/cgi-bin/tools/ESE3/esefinder.cgi.

[8] http://www.fruitfly.org/.

[9] G. Zhang, H. Rodriguez, C. E. Fardella, D. A. Harris, and W. L. Miller, "Mutation T318M in the CYP11B2 gene encoding P450cl1AS (aldosterone synthase) causes corticosterone methyl 
oxidase II deficiency," American Journal of Human Genetics, vol. 57, no. 5, pp. 1037-1043, 1995.

[10] L. Martinerie, S. Viengchareun, A.-L. Delezoide et al., "Low renal mineralocorticoid receptor expression at birth contributes to partial aldosterone resistance in neonates," Endocrinology, vol. 150, no. 9, pp. 4414-4424, 2009.

[11] M. Wasniewska, F. De Luca, M. Valenzise, F. Lombardo, and F. De Luca, "Aldosterone synthase deficiency type I with no documented homozygous mutations in the CYP11B2 gene," European Journal of Endocrinology, vol. 144, no. 1, pp. 59-62, 2001. 


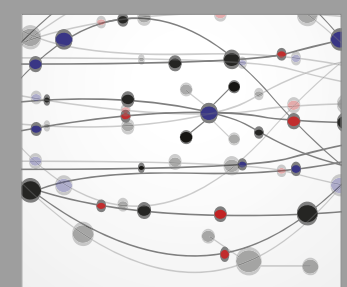

The Scientific World Journal
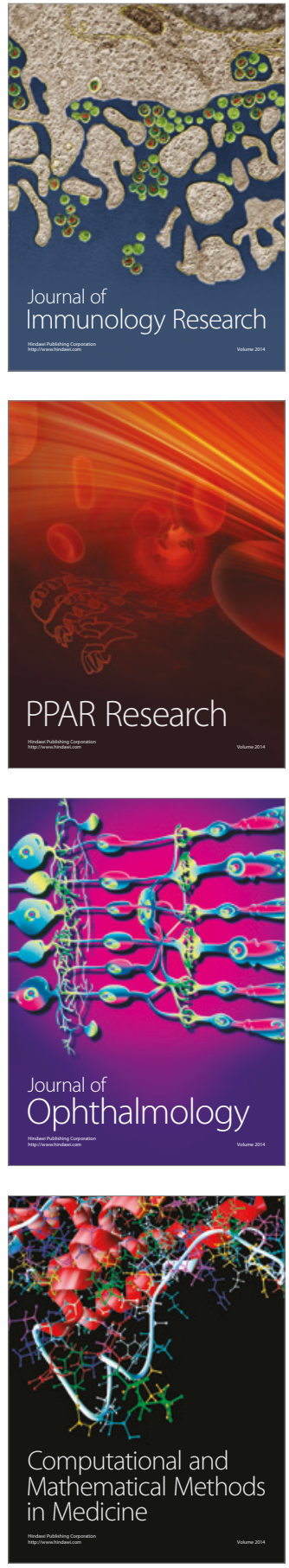

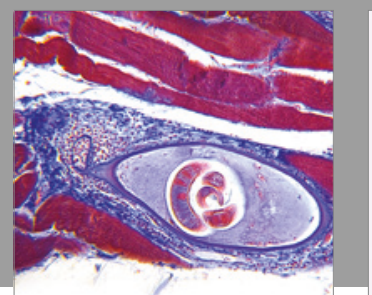

Gastroenterology Research and Practice
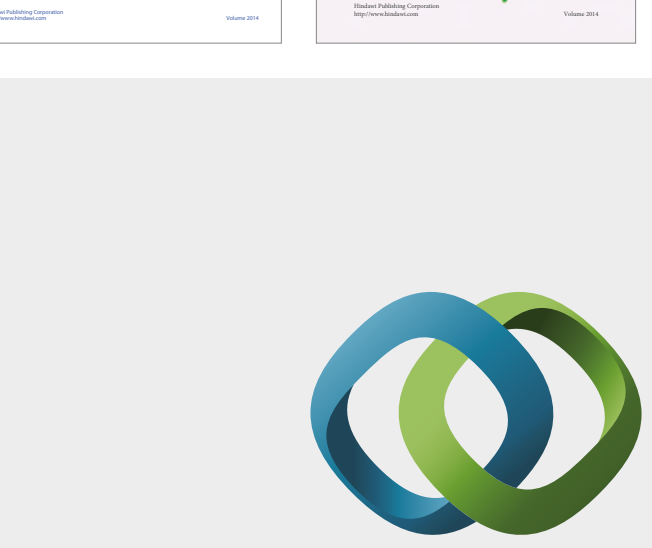

\section{Hindawi}

Submit your manuscripts at

https://www.hindawi.com
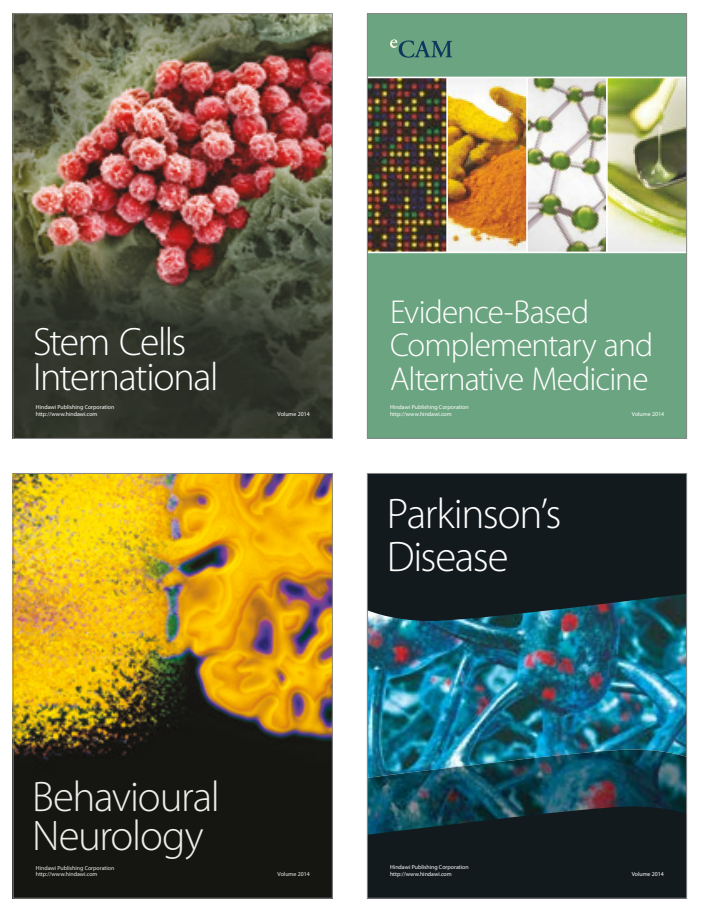
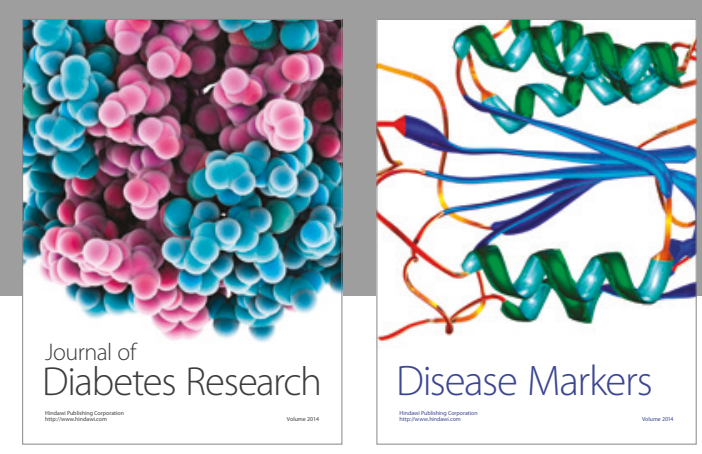

Disease Markers
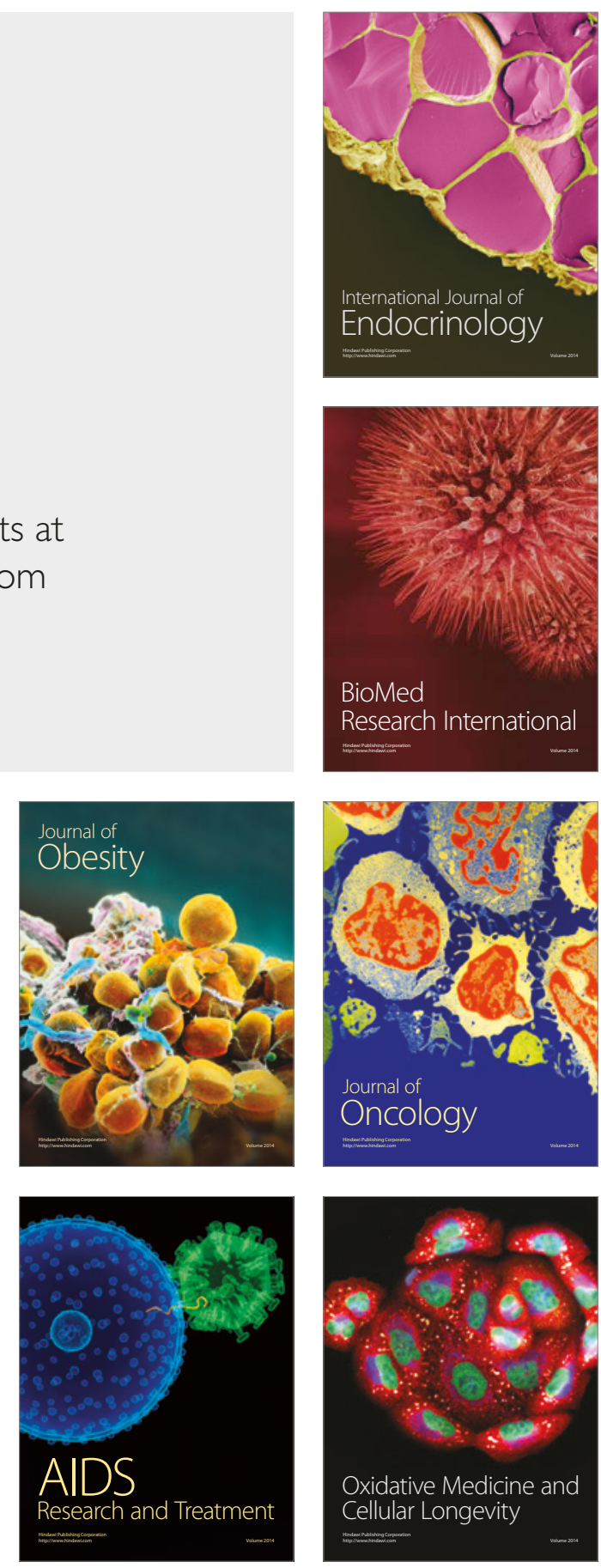